\title{
Do (Ab)Users of Psychedelics Have Tendencies to Abuse High Authority? An Internet Snapshot Study
}

\author{
Ahmed Al-Imam ${ }^{1,2} \&$ Ban A. AbdulMajeed ${ }^{3}$ \\ ${ }^{1}$ Department of Postgraduate Medicine, School of Life and Medical Sciences, University of Hertfordshire, United \\ Kingdom \\ ${ }^{2}$ Department of Anatomy and Cellular Biology, College of Medicine, University of Baghdad, Iraq \\ ${ }^{3}$ Department of Pathology and Forensic Medicine, College of Medicine, Al-Nahrain University, Iraq \\ Correspondence: Dr Ahmed Al-Imam, House 18/5, Al-Akhtal Street, District 318, Al-Adhamyia, 10053, Baghdad, \\ Iraq. E-mail: tesla1452@gmail.com; a.m.al-imam@herts.ac.uk
}

Received: July 25, 2017 Accepted: August 17, 2017 Online Published: September 18, 2017

doi:10.5539/gjhs.v9n11p148

URL: https://doi.org/10.5539/gjhs.v9n11p148

\begin{abstract}
Background: Hallucinogenic substances, also known as psychedelics and entheogens, represent a subset of novel psychoactive substances. The epidemiology of (ab)use and electronic commerce of Psychedelics has been well-mapped in the developed world. However, countries from the developing world are yet to be explored. Principles of psychology including thematic psychoanalysis were not implemented before in connection with psychedelics.
\end{abstract}

Materials and Methods: This study is based on an internet snapshot technique; it will explore and analyse the comments of psychedelics' (ab)users in relation to the possibility of abuse of some granted power (authority); several demographic parameters of $(\mathrm{ab})$ users will be explored. The snapshot will implement thematic analysis and psychoanalysis of comments found on drug fora and social communication media.

Results: The highest contribution of psychedelic users existed in the developed world, while the developing countries including the Middle East contributed the least. More than half (57\%) of Psychedelic (ab)users tend to misuse power, which may indicate an existing psychopathology.

Conclusion: Psychedelic users tend to mishandle the use of authority. The prevalence of psychedelic (ab)users in the Middle East is considered to be minimal. Additional analyses are required and in different populations of students, academics, medical professionals, psychiatric patients, prisoners, terrorists, and military organisations.

Keywords: Novel Psychoactive Substances, NPS, Hallucinogens, psychedelics, observational study, internet snapshot, power, prevalence, epidemiology, public health, community medicine

\section{Backgrounds}

The electronic commerce of novel psychoactive substances (NPS), also known as the NPS e-commerce, has been ever growing over the last two decades; this exponential growth has taken many forms, including the e-commerce on both divisions of the web, surface and deep (Al-Imam et al., 2016; Al-Imam, 2017; Al-Imam et al., 2017; Brew, 2016; Krabseth et al., 2016; Orsolini et al., 2016). Hallucinogens, also known as psychedelics and entheogens, represent a chemical subset under the wider scheme of NPS; psychedelics alter the mental status and induce a hallucinogenic experience (psychedelic trip) via their selective action on central monoamines and monoamine transporters (MATs), and specifically serotonin transporters (Dargan \& Wood, 2013; Gonzalez-Maeso \& Sealfon, 2009; Krebs \& Johansen, 2013; Stafford, 2013). The individual basis of power, explored via social sciences and psychology, include the structural, personal, and cognitive basis of authority (French and Raven 1959; Wrong, 1980). In this study, a critical component of structural power, represented by coercion and punishment, will be explored. Humans tend to rely on those bases of power in their day to day interpersonal interaction from a social and a professional perspective (Mossholder et al., 1993; Podsakoff, Schriescheim, \& Rogers, 1974; Raven, 1993). It is unknown whether psychedelic users behave the same or deviate from the norms with regards to the components of the individual basis of power. Would (ab)users of hallucinogenic agents abuse or shy away from exploiting a granted high power? The study will aim to answer this crucial question.

This study is cross-sectional in nature; it will rely on the internet snapshot technique, which was taken for specific 
groups (or pages) on drug fora and virtual social communication media (Erowid.org, 2017; Facebook, 2017). The study will be enacted in a population of (ab)users of psychedelic substances (hallucinogens); it will analyse threads of commentaries created by psychedelic users with an aim to explore and investigate their tendencies to abuse a given high power and authority, even if the power is fictional. As a whole, there will be an exploration of the linguistic preferences and the potential existence of psychopathology among (ab)users. The overall level-of-evidence of these integrative analyses is estimated to be of level-2b in accordance with the classification system imposed by the Oxford Center for Evidence-Based Medicine (University of Oxford, 2009). The study has been ethically approved by the Institutional Review Board at the College of Medicine-University of Baghdad.

\section{Materials and Methods}

An internet snapshot was taken for the comments of (ab)users of psychedelics substances (hallucinogens); these observations were systematically carried out on specific groups on the Facebook social communication medium and online drug fora (Erowid.org, 2017; Facebook. Magic Mushroom (Psilocybin), 2017; Facebook. Psychedelic Experience, 2017; Facebook. Psychedelic Heaven, 2017; Facebook. Psychedelics \& Philosophy 2, 2017; Facebook. The Adult Psychedelic Sweet Shop, 2017; Facebook. The Terance McKenna Experience, 2017). These groups and fora are dedicated for psychedelic users where they interact socially, share subjective experiences about psychedelic "trips", and comment on a plethora of philosophical topics (Boyer et al., 2007; Van Hout et al., 2013; Van Hout et al., 2014).

This study is observational and cross-sectional in nature; the internet snapshot was taken on the $5^{\text {th }}$ of March 2017. Some interesting threads were noticed; the topics of these threads were related to the same theme, power and authority, including interesting questions; What will you do if you become God?, What will you do if you were given supreme powers? These threads of commentaries are valuable from a psychological perspective and can be explored via thematic (psycho)analysis of comments (De Ganck et al., 2015; Pérez et al., 2015). The aim is to conclude whether psychedelic (ab)users tend to abuse high power and authority. The individual bases of power are structural, personal, and cognitive (French and Raven 1959; Wrong, 1980). In this study, a critical component of structural power, known as coercion and punishment, will be explored in relation to a particular population of web users (psychedelic users). Threads of commentaries of 264 (ab)users were analysed for gender (1), geographic location (2); the number of words per comment (3), and the theme comments (4). The sexual identity (gender) for psychedelic users was concluded from their profile names via using an already established database for the correlation of name versus gender. The geographic mapping (geo-mapping) was deducted from the profile page of each user, whenever disclosed publically. The content (theme) for each comment was categorised into either positive $(\mathrm{P})$, negative $(\mathrm{N})$, or uncategorizable $(\mathrm{U})$.

The total number of analysed psychedelics users was $264(\mathrm{n}=264)$. The Implemented statistical analyses were descriptive and inferential. Statistical analyses were carried out via Microsoft Excel 2016; an alpha ( $\alpha$ ) value of 0.05 and a confidence interval of $95 \%(95 \% \mathrm{CI})$ were considered as the cutoff limit for statistical significance. The study has been approved by the Institutional Review Board (IRB) of the College of Medicine-University of Baghdad; approval has been granted under the authority of IRB meeting number 7 which took place on the $20^{\text {th }}$ of December 2016. The level-of-evidence of this study is level-2b in accordance with the categorization system scheme imposed by the Oxford Center for Evidence-Based Medicine (University of Oxford, 2009).

\section{Results and Discussion}

The number of words per comment (WPC) averaged 14.6 words. Exceptional (statistical outliers) included any comment with 31 up to 224 words (Figure 1). The majority of commenting psychedelics users were males (85.2\%) and females (14.8\%). Positive (optimistic) and negative (pessimistic) ideas were diverse; examples of these comments; Destroy the universe, Create another reality where evil doesn't exist, Suicide, Kill myself, Destroy all humans. The overall theme of observations (Figure 2) was either negative $(57.6 \%)$, positive $(27.3 \%)$, or uncategorizable-unspecific (15.2\%). Further, the contribution of males and females within each thematic category were found to be proportional. 

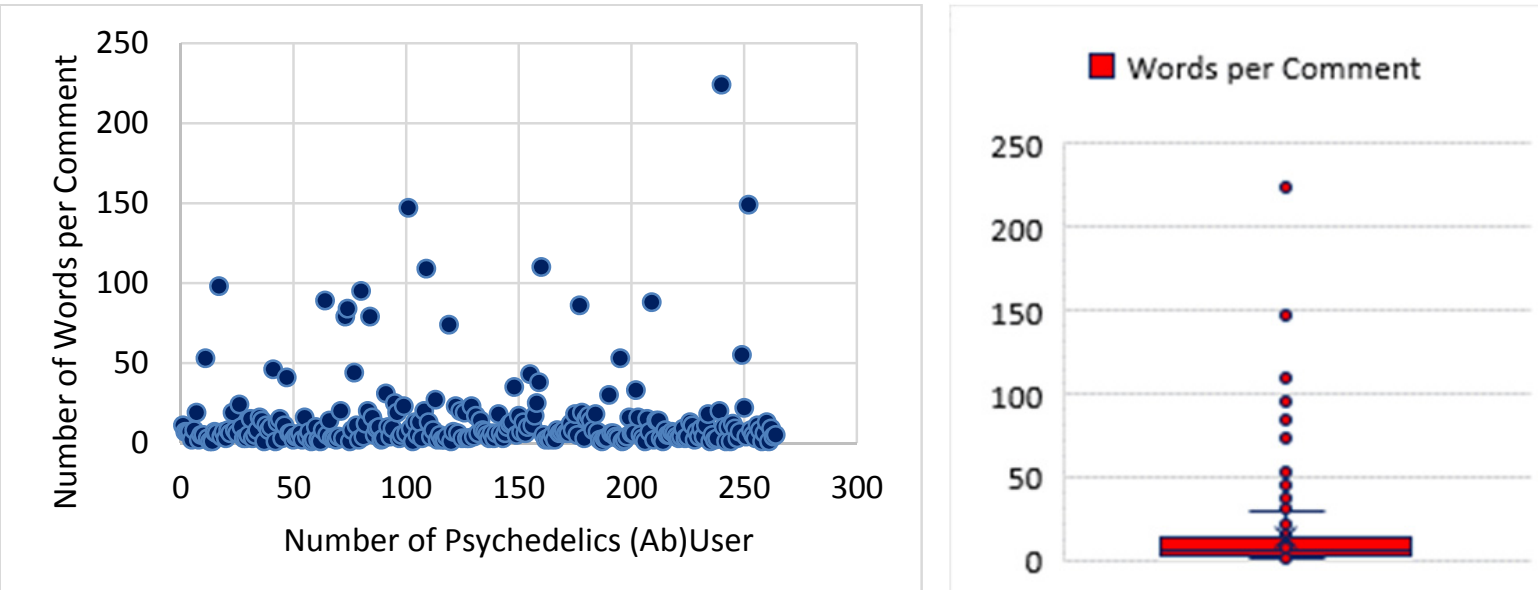

Figure 1. Number of Words per Comments: Scattered Graph (left) and Boxplot (right)

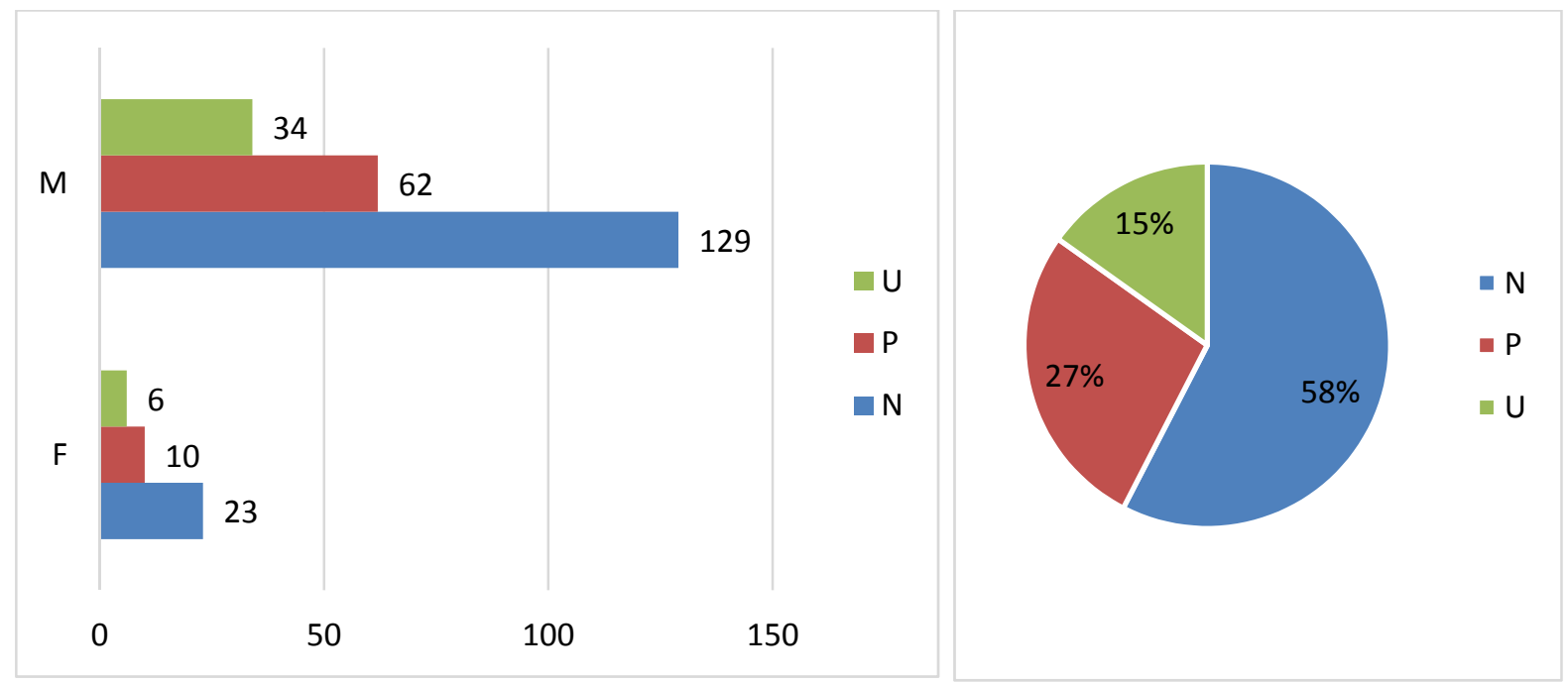

Figure 2. The Proportional Contribution of Psychedelic (Ab)users by Gender, Male $(\mathrm{M})$ and Female $(\mathrm{F})$, to the Theme of Commentaries: Negative (N), Positive (P), and Uncategorizable (U)

The geo-mapping has concluded that the highest proportion of psychedelics (ab)users were from developed countries and the western world (Figures 3 to 5) especially from the United States, United Kingdom, Canada, and Western Europe. On the other hand, the Middle Eastern and Arabic countries contributed the least. Top contributing countries to negative comments included (in a descending order of frequency); US, UK, Canada, Germany, Netherlands, Australia, Bulgaria, Croatia, Russia, and Sweden. Middle Eastern and Arabic countries included Iran, Morocco, and Turkey. Top contributing countries in relation to positive comments included; US, UK, Canada, Netherlands, Australia, Belgium, Denmark, Italy, Sweden, and the Czech Republic. Middle Eastern and Arabic countries included Israel, Turkey, and Iraq. Top contributing countries in relation to uncategorizable comments included; US, UK, Mexico, Germany, Sweden, Romania, Malaysia, Lithuania, Israel, Denmark, and China. Exceptional (statistical outliers) contributing countries included three countries all of which were from the developed western world; these were the US, UK, and Canada. 


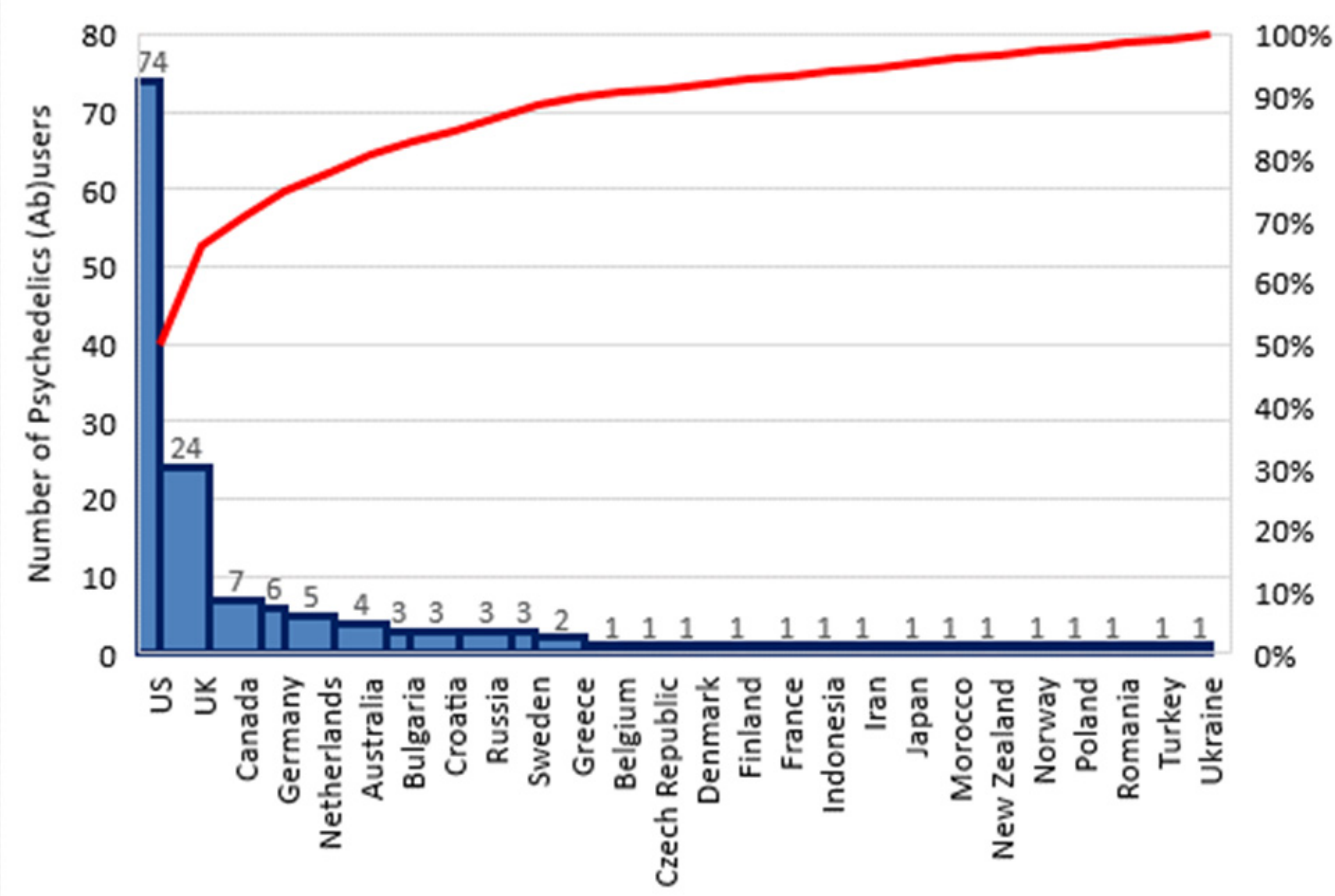

Figure 3. Geo-mapping for Psychedelics (Ab)users with Negative Comments

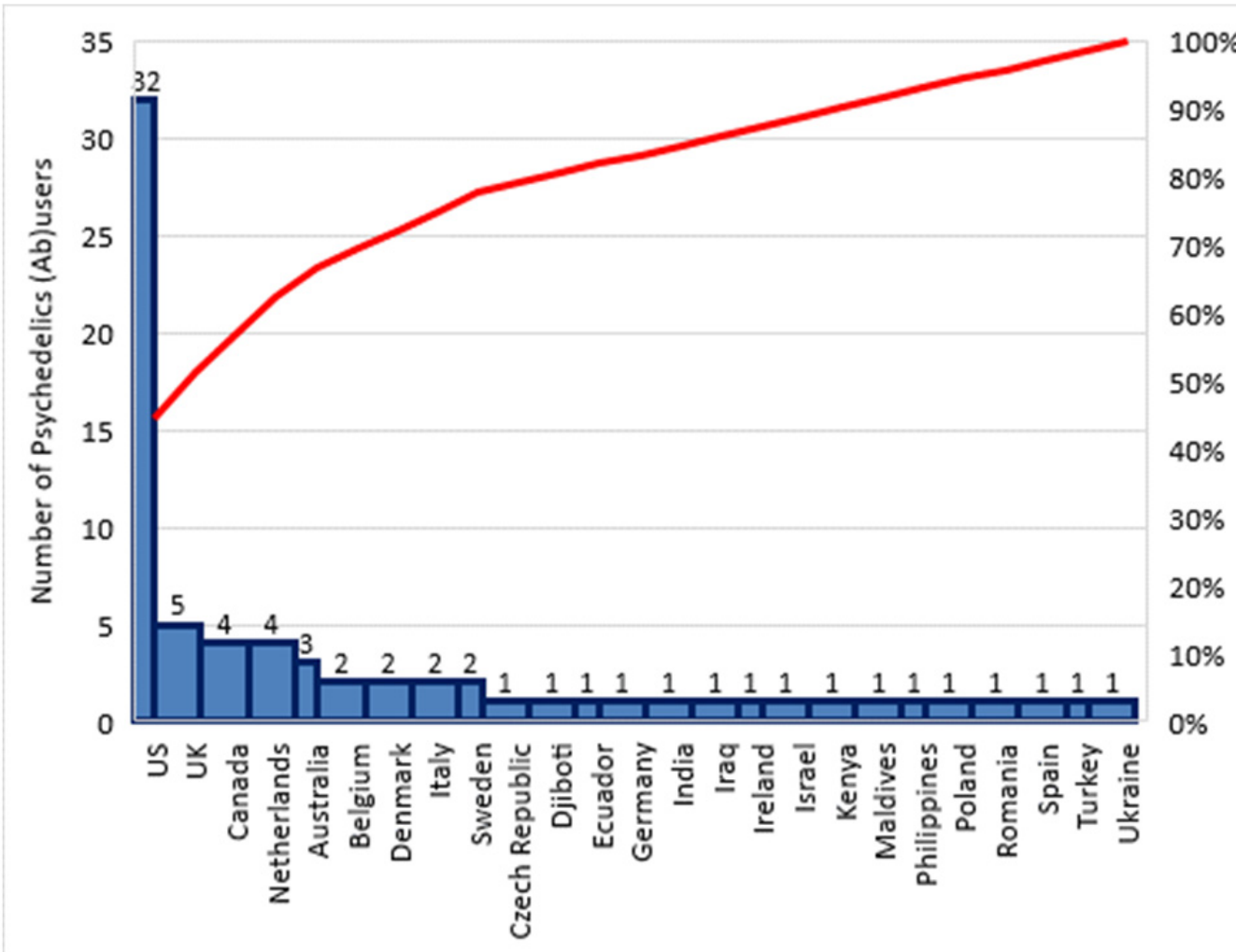

Figure 4. Geo-mapping for Psychedelics (Ab)users with Positive Comments 


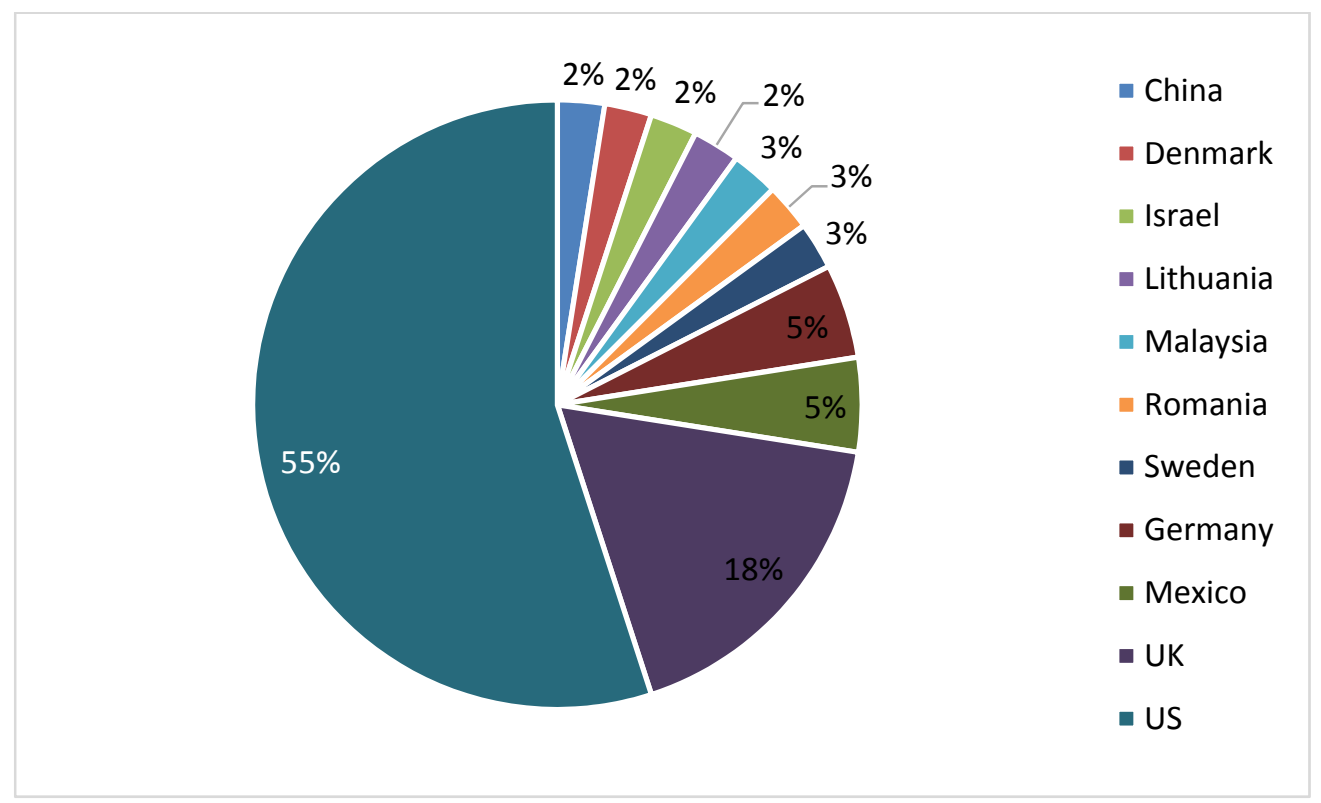

Figure 5. Geo-mapping for Psychedelics (Ab)users with Uncategorizable Comments

ANOVA test was used for the analysis of the number of words per comment versus the theme of comments (positive, negative, and uncategorizable), for which there was a statistically significant difference ( $p$-value $<0.001)$. The number words per comment (Figure 6) averaged; $10.8(\mathrm{~N}), 24.4(\mathrm{P})$, and $11.6(\mathrm{U})$. Additional inferential statistics were carried out using Student's t-test (Figure 7); there was no significant difference in between the length of negative and uncategorizable comments $(\mathrm{p}=0.404)$. On the other hand, psychedelic users with the positive theme (optimistic users) commented significantly more than users with negative comments $(p=0.001)$, and uncategorizable comments $(\mathrm{p}=0.005)$. It is to be concluded that psychedelic users with positive ideas tend to speak and elaborate, while other users (negative and uncategorizable) tend to be brief in their commentaries. Student's t-test was also used to detect any significant difference in the length of comments between males and females; males were found to discuss more (more words per comment) than females regardless of the theme (positivity-negativity) of the commentary ( 15.7 versus 8.2 , $p$-value $=0.012$ ).

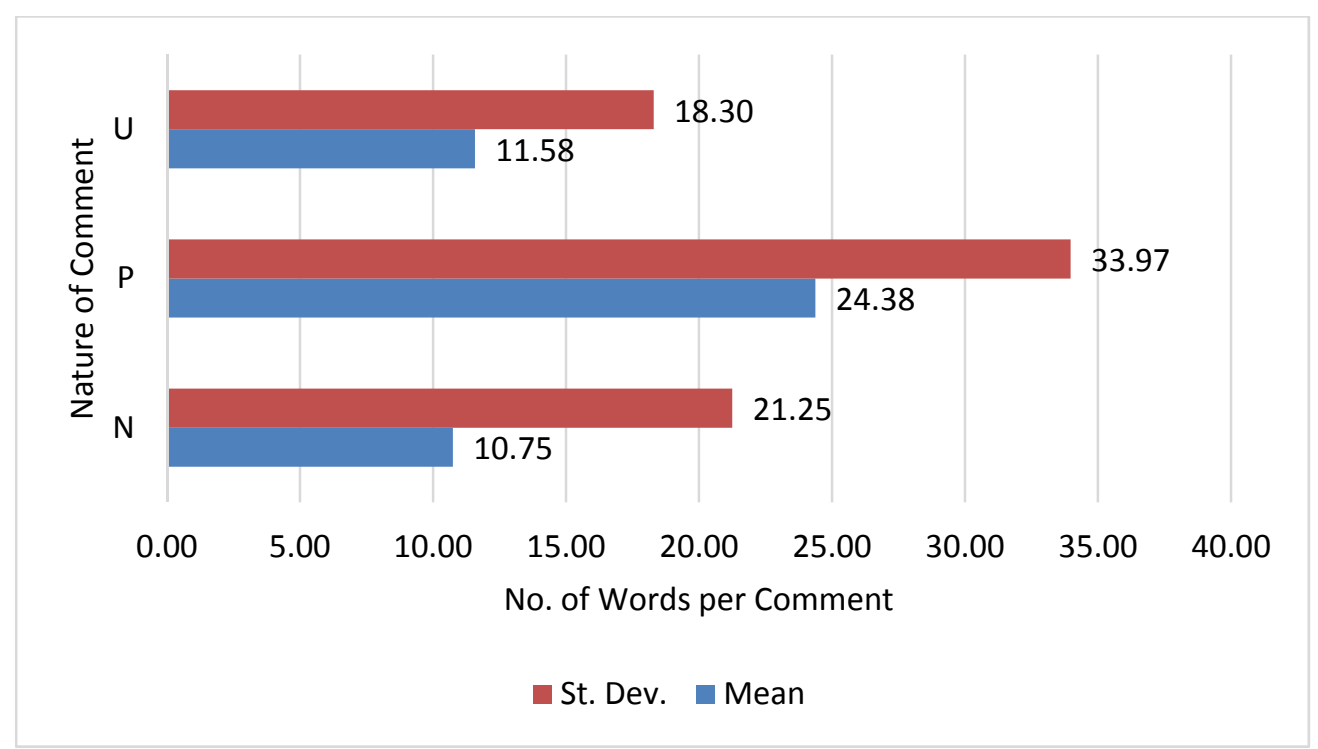

Figure 6. Descriptive Statistics (Mean and Standard Deviation) for the Number of Words per Comment for the Three Themes of Comments: Negative (N), Positive (P), and Uncategorizable (U) 


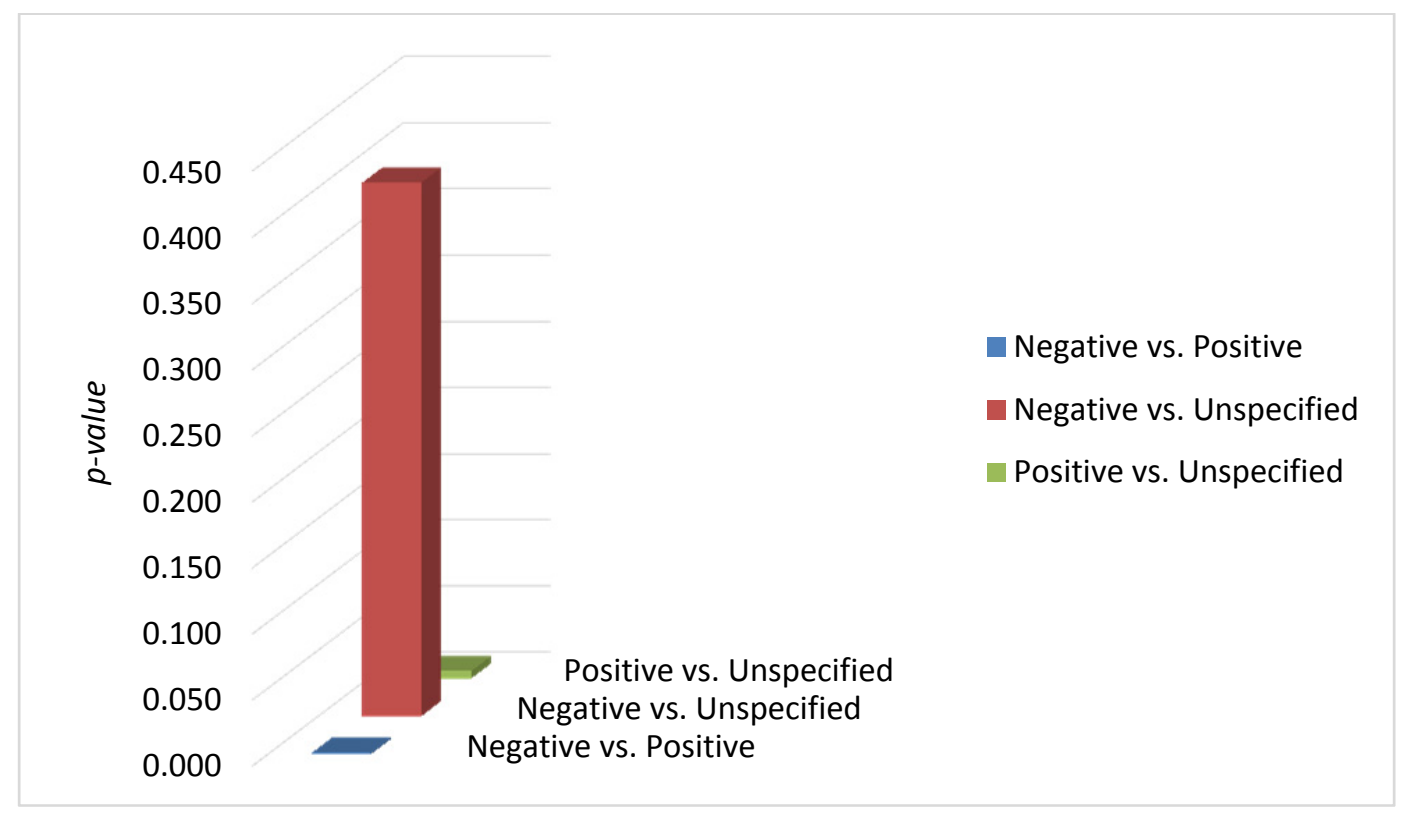

Figure 7. Inferential Statistics (Student's t-test): Number of Words per Comment versus the Theme of Comments

Linear regression was also constructed for the correlation of; gender versus nature (theme) of comment (1), words per comment versus theme of comment (2), and gender versus words per comment (3). Each of the gender (sex) and theme of comments was numerically encoded to enable this analysis. It appears that sex (gender identity) and themes of comments were not correlated $\left(R^{2}\right.$ score $\left.=0.0003\right)$. Additionally, males and females contributed proportionally in relation to all themes of comments (P, N, and $\mathrm{U})$. However, females tend to comment with fewer words $\left(\mathrm{R}^{2}=0.0102\right)$ unless their comments are positive. The conclusion, inferred via Student's t-test, that positive comments tend to be more elaborate was also confirmed via linear regression $\left(\mathrm{R}^{2}=0.057\right)$. To re-encapsulate, males and females contribute proportionally to all three themes of comments; positive commenters tend to elaborate with more words as if they were enthusiastic to make an impact on the world. However, females tend to comment less unless their commentaries were labelled as positive. To be concluded, psychedelic users possess a tendency to abuse a given power; there was no significant difference in relation to the proportional contribution of men and women to this trend. Accordingly, psychedelics users of both genders may behave differently from a normal population (psychedelics-free population) when they are granted a high power. The aetiology and mechanisms behind the phenomenon of abusing authority towards coercion and punishment are beyond the scope of this study, although these can be related to either an inherent or an acquired psychopathology or a combination of both. The potential role of psychedelics as a stimulant towards this behavioural attitude is to be explored in future studies.

\section{Conclusion}

The (ab)users of hallucinogenic NPS tend to mishandle the use of authority. The vast majority of (ab)users were; young, predominantly males, and from the western developed countries; the Middle East contribution was insignificant. Men and women contributed proportionally in relation different themes of comments of relevance to a fictional granted supreme (or divine) power. Those who contributed with positive (optimistic) comments tend to elaborate and discuss their ideas; they were talkative and passionate of how they wanted to change the world to be a better place. However, those optimistic psychedelic users represented a minority within the studied population.

\section{Competing Interests Statement}

The authors have no conflict of interest to be declared.

\section{Source of Funding}

This study was entirely self-funded.

\section{References}

Al-Imam, A. (2017). Could Hallucinogens Induce Permanent Pupillary Changes in (Ab) users? A Case Report from New Zealand. Case Reports in Neurological Medicine, 2017. https://doi.org/10.1155/2017/2503762

AL-Imam, A., Santacroce, R., Roman - Urrestarazu, A., Chilcott, R., Bersani, G., Martinotti, G., \& Corazza, O. 
(2017). Captagon: use and trade in the Middle East. Human Psychopharmacology: Clinical and Experimental, $32(3)$.

Al-Imam, A., Simonato, A. P., \& Corazza, O. (2016). Haloperidol, an old antipsychotic with potential use by NPS users in Iraq. Research and Advances in Psychiatry, 3(3), 81-84. Retrieved from https://www.rapjournal.eu/materiale_cic/948_3_3/8031_haloperidol/article.htm

Brew, I. (2016). Novel psychoactive substances. The British Journal of General Practice, 66(644), 125. https://doi.org/10.3399/bjgp16X684253

Dargan, P., \& Wood, D. (Eds.). (2013). Novel psychoactive substances: classification, pharmacology and toxicology. Academic Press.

De Ganck, J., \& Vanheule, S. (2015). "Bad boys don't cry": a thematic analysis of interpersonal dynamics in interview narratives of young offenders with psychopathic traits. Frontiers in psychology, 6. https://doi.org/10.3389/fpsyg.2015.00960

Erowid.org/. Erowid. Retrieved from https://www.erowid.org/ (accessed 16 March 2017).

Facebook. Facebook. Retrieved from https://www.facebook.com/ (accessed 16 March 2017).

Facebook. Magic Mushroom (Psilocybin). Retrieved 16 March, 2017, from https://www.facebook.com/groups/1546595612323918/

Facebook. Psychedelic Experience. Retrieved 16 March, 2017, from https://www.facebook.com/groups/815158201837615/

Facebook. Psychedelic Heaven. Retrieved 16 March, 2017, from https://www.facebook.com/groups/Psychedelic.Heaven/.

Facebook. Psychedelics \& Philosophy 2. Retrieved 16 March, 2017, from https://www.facebook.com/groups/1233956900000615/permalink/1315808575148780/?comment_id=1315 953378467633-if_t $=$ group_comment $\neg$ if_id $=148742705280730$

Facebook. The Adult Psychedelic Sweet Shop. Retrieved 16 March, 2017, from https://www.facebook.com/groups/763405830462403/

Facebook. The Terance McKenna Experience. Retrieved 16 March, 2017, from https://www.facebook.com/groups/terencemckenna/

French, J. R., Raven, B., \& Cartwright, D. (1959). The bases of social power. Classics of organization theory, 7.

Gonzalez-Maeso, J., \& Sealfon, S. C. (2009). Psychedelics and schizophrenia. Trends in neurosciences, 32(4), 225-232. https://doi.org/10.1016/j.tins.2008.12.005

Krabseth, H. M., Tuv, S. S., Strand, M. C., Karinen, R. A., Wiik, E., Vevelstad, M. S., ... \& Vindenes, V. (2016). Novel psychoactive substances. Tidsskrift for den Norske laegeforening: tidsskrift for praktisk medicin, ny raekke, 136(8), 714-717. https://doi.org/10.4045/tidsskr.15.1278

Krebs, T. S., \& Johansen, P. Ø. (2013). Psychedelics and mental health: A population study. PloS one, 8(8), e63972. https://doi.org/10.1371/journal.pone.0063972

Mossholder, K. W., Bennett, N., Kemery, E. R., \& Wesolowski, M. A. (1998). Relationships between bases of power and work reactions: The mediational role of procedural justice. Journal of Management, 24(4), 533-552. https://doi.org/10.1177/014920639802400404

Schifano, F., Orsolini, L., Duccio Papanti, G., \& Corkery, J. M. (2015). Novel psychoactive substances of interest for psychiatry. World Psychiatry, 14(1), 15-26. https://doi.org/10.1002/wps.20174

Pérez, A., Crick, P., \& Lawrence, S. (2015). Delving into the 'emotional storms': A thematic analysis of psychoanalysts' initial consultation reports. The International Journal of Psychoanalysis, 96(3), 659-680. https://doi.org/10.1111/1745-8315.12356

Raven, B. H. (1993). The bases of power: Origins and recent developments. Journal of social issues, 49(4), 227-251. https://doi.org/10.1111/j.1540-4560.1993.tb01191.x

Rogers, M. F. (1974). Instrumental and infra-resources: The bases of power. American Journal of Sociology, 79(6), 1418-1433. https://doi.org/10.1086/225708

Stafford, P. (2013). Psychedelics encyclopedia. Ronin Publishing. 
University of Oxford. Center for Evidence Based Medicine. Retrieved 16 March, 2017, from http://www.cebm.net/

Wrong, D. H. (1979). Power: Its Forms. Bases, and Uses. London, England: Basil Blackwood.

\section{Copyrights}

Copyright for this article is retained by the author(s), with first publication rights granted to the journal.

This is an open-access article distributed under the terms and conditions of the Creative Commons Attribution license (http://creativecommons.org/licenses/by/4.0/). 